Journal of Patient-Centered

Volume 8

Issue 4 - Cancer Screening

Article 4

10-18-2021

\title{
Improving Cancer Screening Rates in Primary Care via Practice Facilitation and Academic Detailing: A Multi-PBRN Quality Improvement Project
}

Christopher P. Morley

Laura A. Schad

Laurene M. Tumiel-Berhalter

Laura A. Brady

Alexandrea Bentham

Karen Vitale

Amanda Norton

Gary Noronha

Carlos Swanger

Follow this and additional works at: https://aah.org/jpcrr

Part of the Community Health and Preventive Medicine Commons, Family Medicine Commons, Internal Medicine Commons, Neoplasms Commons, Preventive Medicine Commons, Primary Care Commons, and the Quality Improvement Commons

\section{Recommended Citation}

Morley CP, Schad LA, Tumiel-Berhalter LM, Brady LA, Bentham A, Vitale K, Norton A, Noronha G, Swanger C. Improving cancer screening rates in primary care via practice facilitation and academic detailing: a multi-PBRN quality improvement project. J Patient Cent Res Rev. 2021;8:315-22. doi: 10.17294/ 2330-0698.1855

Published quarterly by Midwest-based health system Advocate Aurora Health and indexed in PubMed Central, the Journal of Patient-Centered Research and Reviews (JPCRR) is an open access, peer-reviewed medical journal focused on disseminating scholarly works devoted to improving patient-centered care practices, health outcomes, and the patient experience. 


\title{
Improving Cancer Screening Rates in Primary Care via Practice Facilitation and Academic Detailing: A Multi-PBRN Quality Improvement Project
}

\author{
Christopher P. Morley, PhD, MA,${ }^{1}$ Laura A. Schad, MPH, ${ }^{1}$ Laurene M. Tumiel-Berhalter, $\mathrm{PhD}, 2,3$ \\ Laura A. Brady, PhD, ${ }^{2}$ Alexandrea Bentham, BS, ${ }^{2}$ Karen Vitale, MSEd, ${ }^{4}$ Amanda Norton, MSW, \\ Gary Noronha, MD, ${ }^{6}$ Carlos Swanger, MD ${ }^{6,7}$ \\ ${ }^{1}$ Department of Public Health and Preventive Medicine, State University of New York (SUNY) Upstate Medical \\ University, Syracuse, NY; ${ }^{2}$ Department of Family Medicine, SUNY University at Buffalo, Buffalo, NY; ${ }^{3}$ University at \\ Buffalo Clinical and Translational Science Institute, Buffalo, NY; ${ }^{4}$ University of Rochester Clinical and Translational \\ Science Institute, Rochester, NY; ${ }^{5}$ A. Mandatory, Inc. (consulting for SUNY Upstate Medical University), Groton, NY; \\ ${ }^{6}$ Center for Primary Care, Department of Medicine, University of Rochester School of Medicine and Dentistry, \\ Rochester, NY; ${ }^{7}$ Health Reach for the Homeless, Rochester Regional Health, Rochester, NY
}
Purpose
In the United States, cancer screening rates are often below national targets. This project implemented practice facilitation and academic detailing aimed at increasing breast, cervical, and colorectal cancer screening rates in safety-net primary care practices.
Methods
Three practice-based research networks across western and central New York State partnered to provide quality improvement strategies on breast, cervical, and colorectal cancer screening. Pre/ postintervention screening rates for all participating practices were collected annually, as were means across all practices over 7 years. Simple ordinary least squares linear regression was used to calculate the trend for each cancer type and test for statistical significance (ie, $\mathrm{P} \leq 0.05$ ), using the ordinal time point as a fixed effect.

Results An overall increase in mean screening rates was seen over the duration of this project for colorectal (24.6\% preintervention to $48.0 \%$ in year 7 of intervention; $\mathrm{P}<0.001)$ and breast cancer $(37.0 \%$ preintervention to $48.6 \%$ in year $7 ; \mathrm{P}=0.460)$. Mean cervical cancer screening rates decreased $(35.5 \%$ preintervention to $31.4 \%$ in year $7 ; \mathrm{P}=0.209$ ). Success in increasing screening rates varied across regions of New York State.

Conclusions Practice facilitation and academic detailing were successful in significantly increasing, on average, colorectal cancer screening rate. Cervical cancer screening showed an overall decrease, likely due to difficulties for primary care practices in tracking and implementation, as many patients seek this service at outside gynecology facilities. Regional differences, guideline changes, and practice reorganization each may have played a part in observed trends. A standardization of queries being used to pull screening rates is an important step in increasing the reliability of these data. ( $\mathrm{J}$ Patient Cent Res Rev. 2021;8:315-322.)

Keywords cancer screening; primary care; breast cancer; cervical cancer; colorectal cancer; practice facilitation; academic detailing; quality improvement

I $\mathrm{n}$ the United States, breast cancer is the second most common cancer among women and the second leading cause of death among women after lung cancer. ${ }^{1}$

Corresponding author: Christopher P. Morley,

Department of Public Health and Preventive Medicine, Upstate Medical University, 750 E. Adams St., Weiskotten Hall 2262, Syracuse, NY 13210 (MorleyCP@upstate.edu)
Colorectal cancer is the third most commonly diagnosed cancer in men and women. ${ }^{2}$ However, almost half of all cancers in the United States are preventable; and one common method for early detection is screening, which can help detect both precancerous and cancer cells early while treatment is still a viable option. ${ }^{3,4}$ Historically, cervical cancer was one of the most common causes of cancer death among American women. Due to increased patient acceptance of screening, rates of cervical cancer diagnosis and death have declined rapidly. Over the last 
10 years, however, these rates have stopped improving and have remained stable. ${ }^{5}$

Despite the current evidence of preventive screening effectiveness, rates of breast, cervical, and colorectal cancer in the United States continue to fall below national targets. ${ }^{6}$ Academic detailing (AD) and practice facilitation (PF) are quality improvement (QI) strategies and potential ways to help primary care practices increase screening for these cancers among patients. AD transfers knowledge or methods to physicians, nurses, or office staff through visits by a trained educator, a strategy that has demonstrated usefulness in improving colorectal cancer screening rates in some settings. ${ }^{7,8}$ It relies on the visitation by an academic expert (often a clinician) to deliver information to medical practices in the community. Later in the project, we were able to implement online versions of $\mathrm{AD}$ lectures.

PF uses trained individuals who work with practice staff to conduct QI activities and support evidence-based interventions, which in the project presented herein were aimed at increasing cancer screening. This method has shown success in improving rates of cancer screening among primary care practices, ${ }^{9}$ as well as in other processes such as chronic pain management. ${ }^{10}$ Combining $\mathrm{AD}$ and $\mathrm{PF}$ is one strategy that can be used to increase screening rates in targeted settings. ${ }^{6}$ Together, the $\mathrm{AD} /$ $\mathrm{PF}$ approach represents the engagement, by academia, of primary care practices to assist in the implementation of the most recent evidence and approaches to patient care.

Practice-based research networks (PBRNs) can be used to implement QI across multiple primary care practices. The work of PBRNs is often viewed as community-based participatory research, as it engages community members and patients as stakeholders in research activities. ${ }^{11}$ PBRN projects reflect the patients they serve, addressing the unique needs of the communities with whom they interact. ${ }^{12} \mathrm{PF}$ is a strategy that has been used by PBRNs to facilitate relationships between the academic and clinical settings in a geographic location and can be a useful tool for developing collaborations and promoting community engagement in PBRNs. ${ }^{13,14}$

The primary aims of this QI project was to implement interventions using $\mathrm{AD} / \mathrm{PF}$ to increase breast, cervical, and colorectal cancer screening within primary care practices involved with regional PBRNs and to assess outcomes and barriers to success. Our focus was on "safety-net" practices, ie, those that provide services to populations that are disadvantaged. Related reports also appearing within this issue of Journal of Patient-Centered Research and Reviews (JPCRR) describe details of facilitators and barriers to screening rate improvement ${ }^{15}$ and the impact of the COVID-19 pandemic on screening QI. ${ }^{16}$ Additionally, each year of the project was described in detail to the New York State Department of Health via publicly available annual reports. ${ }^{17-22}$ In this article, we describe the primary screening rate outcomes over the 7-year period of the project.

\section{METHODS}

Under this project, 3 PBRNs administered from State University of New York (SUNY) Upstate Medical University, SUNY University at Buffalo, and University of Rochester Medical Center partnered to provide AD and PF services on breast, cervical, and colorectal cancer screening to safety-net primary care practices across central and western New York State, including regions in and around the cities of Syracuse, Rochester, and Buffalo.

Practices enrolled in the project received an in-person AD session on breast, cervical, and colorectal screening guidelines and strategies to increase rates among eligible patient populations. Later in the project, we were able to move $\mathrm{AD}$ sessions to an online delivery system. In both cases, the lecture was standardized and eligible for continuing medical education credit. Strategies were selected from evidence-based approaches to screening rate improvement and included patient-centered interventions such as case management, portable screening modalities, and patient-centered education and outreach. The practices received $\mathrm{PF}$ services from trained professionals for a minimum 6-month period to develop and implement practice-specific strategies through QI, screening, data, and administrative support, with the same goal of increasing cancer screening among eligible populations. AD was repeated annually, and staff were free to re-attend.

The project was initiated for year 1 (Y1) in the fall of 2013, with a sole focus on colorectal screening - including colonoscopy, fecal occult blood test/ fecal immunochemical test (FOBT/FIT), and flexible sigmoidoscopy - and with a short interventional window of about 4 months (February 2014-May 2014). Beginning in $\mathrm{Y} 2$ and continuing through $\mathrm{Y} 7$, the scope of the project expanded to include breast and cervical cancer screening in addition to colorectal. The PF period also was expanded to 6 months beginning in Y2, a change that lasted through the remainder of the project. Additional details regarding the full scope of the $\mathrm{AD} / \mathrm{PF}$ intervention are described in annual reports for each project year. ${ }^{17-22}$

\section{Longitudinal Measurements}

Longitudinal analyses were conducted to assess changes in cancer screening rates over time among practices that participated in the project on a continuous basis since 
Y1 (3 practices) and Y2 (5 practices). It is important to note that, during $\mathrm{Y} 1$ to $\mathrm{Y} 3$, screening rates were reported twice for each project year, once before the PF period began ("pre") and once following the PF period ("post"). During Y4, the pre-PF measurement of screening rates was eliminated among continuing practices and their postPF measurements from Y3 were considered the "pre" for Y4. Similarly, during Y5, the post-PF measurement from Y4 was considered the "pre" for Y5. In Y6 and Y7, all participating practices were once again required to report their screening rates twice each year.

To collect data, the practice facilitator assigned to each practice provided their key contacts with a data request form twice a year, which included fields (with instructions) for the reporting of cancer rates within the practice for each of the three cancer types, the date range for these data, and the specific guidelines used by the practice to determine screening eligibility. The data for each period were compared with recent periods, and serious or obvious discrepancies were followed up between the facilitator and practice staff. In some cases, practices required assistance with identifying the numerator and denominator for their screening rate calculations, chart audits, the construction of data queries, or other processes. Assistance was provided by the practice facilitator in each case.

More extensive details are available in the annual project reports. ${ }^{17-22}$ Individual medical practices were free to enter or leave the project over the 7-year implementation period.

\section{Analysis}

The overall trends across all participating practices were calculated as a mean cancer screening rate, for each cancer type, at each of 14 time points (beginning with baseline data as of January 2013 and then reflecting pre/ post-PF periods) for colorectal cancer and 12 time points (August 2014 baseline) for breast and cervical cancer. Simple ordinary least squares linear regression was used to calculate the trend for each cancer type and to test whether trends were statistically significant (at alpha of $\mathrm{P} \leq 0.05$ ), using the ordinal time point as a fixed effect.

As a multipractice QI process, the analysis was conducted as an observational evaluation of effectiveness, and explicit detail about individual practices or practice types has been shielded to prevent intentional or accidental identification. However, we have included trends in individual regions. First, a priori testing for regional effects was conducted in two ways, first, by adding and eliminating (through backward stepwise elimination) regional dummy variables, iteratively, to the ordinary least squares regression model or screening rates over time for each cancer type. Mean cancer screening rates for each of the three cancer types, over the duration of the project, were compared via 1-way analysis of variance (ANOVA). Then, individual trends were evaluated for each individual region, by each cancer type, again using simple ordinary least squares regression with the ordinal time point as a fixed effect. There were distinct characteristics to the practices around the three cities; one region was predominated by loose affiliates of a single health system, including several population-specific Federally Qualified Health Centers (FQHCs); a second consisted primarily of urban FQHCs; and the third was a mix of rural and urban FQHCs and academic practices. Because the identity of the individual practices is confidential, we additionally analyzed the effects by region.

All analyses presented herein were conducted in IBM $^{\circledR}$ SPSS ${ }^{\circledR}$ Statistics software (version 26, IBM Corporation). Other analyses focused on process and implementation of the interventions, qualitative assessment of barriers and facilitators of cancer screening,${ }^{15}$ and the impact of the COVID-19 pandemic on screening rates; ${ }^{16}$ these outcomes were analyzed separately and are not presented in this work. All work was conducted under a finding by the institutional review board of SUNY Upstate Medical University that this multisite QI project did not meet the definition of research.

\section{RESULTS}

A total of 29 practices participated in the project over the 7 -year period of engagement. The initial year included 9 practices, focused solely on colorectal cancer screening rate improvement; the second year saw an expansion, with the number of practices providing colorectal screening rates increasing to 24 and inclusion of interventions to improve breast and cervical cancer screening (23 and 20 practices per screening type, respectively). Table 1 breaks down the number of participating practices, by cancer

Table 1. Number of Practices Participating and Providing Screening Data, by Year and Cancer Type

\begin{tabular}{lccc}
\hline Project year & Colorectal & Breast & Cervical \\
\hline Year 1 & 9 & 0 & 0 \\
Year 2 & 23 & 24 & 20 \\
Year 3 & 13 & 12 & 12 \\
Year 4 & 13 & 13 & 12 \\
Year 5 & 13 & 13 & 11 \\
Year 6 & 12 & 12 & 11 \\
Year 7 & 12 & 12 & 12 \\
\hline
\end{tabular}


type, per year. Table 2 illustrates limited information about each practice, including type of practice, years of project participation, and any notes about changes in practice type or ownership, by region.

\section{Comparisons of All Practices by Project Period}

As previously mentioned, the focus of Y1 was to collect and evaluate colorectal cancer screening rates conducted via colonoscopy, FOBT/FIT kits, and flexible sigmoidoscopy.
Nine practices began participation during the Y1 project period, with a mean colorectal screening rate of $24.6 \%$ for the pre-Y1 time point. At the post-Y7 time point, the mean rate was $48.0 \%$, an overall increase across all practices of 23.4 percentage points over 7 years and a positive and significant linear trend over time $(\beta$ : $1.538 ; \mathrm{P}<0.001)$. The greatest increase in colorectal screening between two consecutive time points for this group was from post-Y1 to pre-Y2, a 5.8 percentage point increase.

Table 2. Breakdown of Safety-Net Practice Characteristics, Project Years (1-7), and Notes

\begin{tabular}{|c|c|c|c|}
\hline Region & Practice category ${ }^{a}$ & \begin{tabular}{|l|} 
Years \\
participated
\end{tabular} & Notes (practice changes) \\
\hline 1 & $\begin{array}{l}\text { Physician-owned practice } \\
\text { Large medical group/health system } \\
\text { Large medical group/health system } \\
\text { University hospital/clinic } \\
\text { Large medical group/health system } \\
\text { Large medical group/health system } \\
\text { Large medical group/health system } \\
\text { Large medical group/health system } \\
\text { Large medical group/health system } \\
\text { Nonprofit clinic } \\
\text { Large medical group/health system } \\
\text { Physician-owned practice }\end{array}$ & $\begin{array}{l}1-7 \\
2-7 \\
2-7 \\
2-5 \\
2-7 \\
2 \\
2 \\
2 \\
2 \\
1 \\
2 \\
2\end{array}$ & $\begin{array}{l}\text { University hospital/clinic } Y 1 \text { \& Y2, nonprofit } \\
\text { clinic Y3 \& Y6, large medical group/health } \\
\text { system Y4, physician-owned practice Y5 \& Y7 } \\
\text { University hospital/clinic Y2-Y5 } \\
\text { University hospital/clinic Y2 \& Y3 } \\
\text { Physician-owned practice Y2-Y4 } \\
\text { University hospital/clinic Y2 \& Y3 }\end{array}$ \\
\hline 2 & $\begin{array}{l}\text { FQHC } \\
\text { FQHC } \\
\text { FQHC } \\
\text { FQHC } \\
\text { Large medical group/health system } \\
\text { Large medical group/health system } \\
\text { FQHC } \\
\text { FQHC } \\
\text { Large medical group/health system } \\
\text { Large medical group/health system }\end{array}$ & $\begin{array}{l}1-7 \\
1-7 \\
2-7 \\
2-7 \\
1,2 \\
4-7 \\
2 \\
2 \\
1 \\
2\end{array}$ & $\begin{array}{l}\text { Large medical group/health system Y1-Y4 } \\
\text { Large medical group/health system Y1-Y5 } \\
\text { Large medical group/health system Y2-Y5 } \\
\text { FQHC Y4-Y6 }\end{array}$ \\
\hline 3 & $\begin{array}{l}\text { University hospital/clinic } \\
\text { Nonprofit clinic } \\
\text { FQHC } \\
\text { FQHC } \\
\text { Physician-owned practice } \\
\text { FQHC } \\
\text { FQHC }\end{array}$ & $\begin{array}{l}1-7 \\
1-5 \\
3,4 \\
3,5-7 \\
2 \\
1,2 \\
6,7\end{array}$ & Physician-owned practice $\mathrm{Y} 1-\mathrm{Y} 3$ \\
\hline
\end{tabular}

${ }^{a}$ Practice category reported for most recent year of practice participation.

FQHC, Federally Qualified Health Center. 
Table 3. Cancer Screening Rates Across 14 Time Points

\begin{tabular}{|c|c|c|c|}
\hline \multirow[b]{2}{*}{ Time point } & \multicolumn{3}{|c|}{ Screening rate per cancer type } \\
\hline & Colorectal & Breast & Cervical \\
\hline January 2013 & 24.57 & - & - \\
\hline June 2014 & 26.97 & - & - \\
\hline August 2014 & 32.75 & 36.95 & 35.52 \\
\hline June 2015 & 38.34 & 49.85 & 38.77 \\
\hline August 2015 & 42.48 & 49.47 & 30.75 \\
\hline June 2016 & 41.11 & 48.75 & 36.44 \\
\hline August 2016 & 42.40 & 53.44 & 35.94 \\
\hline June 2017 & 43.82 & 51.18 & 30.95 \\
\hline August 2017 & 43.58 & 51.35 & 33.92 \\
\hline June 2018 & 46.76 & 42.67 & 34.29 \\
\hline August 2018 & 47.96 & 46.43 & 32.01 \\
\hline June 2019 & 42.96 & 48.36 & 31.17 \\
\hline August 2019 & 49.64 & 47.77 & 31.69 \\
\hline June 2020 & 47.96 & 48.64 & 31.35 \\
\hline Linear trend ${ }^{a}$ & $\begin{array}{c}1.538 \\
(<0.001)\end{array}$ & $\begin{array}{c}0.376 \\
(0.354) \\
\end{array}$ & $\begin{array}{l}-0.494 \\
(0.209) \\
\end{array}$ \\
\hline
\end{tabular}

a Linear trends summarized by $\beta$ ( $P$-value).

Screening interventions began in Y2 for breast and cervical cancer. Breast screening rates increased from a mean of $37.0 \%$ to $48.6 \%$ from $\mathrm{Y} 2$ to the final measurement at $\mathrm{Y} 7$, with a slightly positive but nonsignificant trend ( $\beta$ : 0.376; $\mathrm{P}=0.354$ ). Mean cervical screening rates decreased from the initial period, at $35.5 \%$, to $31.4 \%$ at $\mathrm{Y} 7$, with a slightly negative but nonsignificant trend $(\beta$ : $-0.494 ; \mathrm{P}=0.209)$. Complete year-by-year rates are shown in Table 3.

\section{Overall Cancer Screening Rates by Practice Region} Region 1 saw significant increases in both mean colorectal $(17.7 \%-56.0 \%, \beta: 2.957 ; \mathrm{P}<0.001)$ and breast cancer $(31.3 \%-62.2 \%, \beta: 2.652 ; \mathrm{P}<0.001)$ screening rates, as well as a small but nonsignificant mean increase in cervical cancer screening $(25.9 \%-28.5 \%, \beta$ : 0.691 ; $\mathrm{P}=0.291$ ). Region 2 saw decreases in the mean screening rates for all cancer types, with the largest decrease occurring among cervical cancer screening. Region 3 realized increased mean screening rates for all cancer types, with the strongest, and only significant, change in colorectal cancers $(13.4 \%-55.6 \%, \beta$ : 2.957; $\mathrm{P}<0.001)$. Detailed results are reported in Table 4.

\section{DISCUSSION}

Practice facilitation, augmented by academic detailing, was a key part of increasing colorectal cancer screening rates over time and likely had an impact on breast cancer screening as well. The significant overall increase in screening rates from pre-Y1 to post-Y7 for colorectal cancer supports the idea that $\mathrm{AD} / \mathrm{PF}$ may have been successful in increasing the screening for this cancer. While not statistically significant, breast cancer screening also showed an overall increase from pre-Y2 to post-Y7, showing success in some practices.

The negative, though nonsignificant, change over time for cervical cancer screening rates is not surprising, as it continues to be difficult for primary care practices to target and track these patients because many seek this service at outside obstetrics/gynecology (OB/GYN) facilities, which were beyond the scope of this project. Sharing information across practice sites requires dedicated effort, and it is possible that participating practices shifted focus when not engaged with the project team. Additionally, some practices themselves don't offer the screening, as their providers are not comfortable offering and performing it, even when they have been trained to do so. Many of the practices who participated in $\mathrm{Y} 7$ of the project stated that they were not comfortable with their cervical screening rate reports because they are more difficult to update and track than the other screening types.

Regionally, there were differences in the success that practices had in increasing their screening rates from pre-Y2 to post-Y7. Changes in average screening percentages varied not only between regions but among varying cancer types within regions. Region 1 appeared to be the most successful region, with statistically significant increases in both colorectal and breast cancer screening and a nonsignificant increase in cervical cancer screening. This region utilized a mobile mammography unit that was well-known and connected in the region to address transportation issues with patients. Region 2 saw decreases in average rates for all cancer types, with the largest decrease occurring in cervical cancer screening. Throughout the 7 years of the project, this region was heavily impacted by organization changes. In addition to practice and organizational changes, Region 2 had participating specialty clinics that serve transient populations, including the homeless and refugees. Conducting patient outreach in these clinics is often difficult, and many are lost to follow-up. Limited transportation also impacts screening rates in these practices, as do many other social determinants. Region 3 had positive mean screening rates for all three cancers over time, with the strongest, and only significant, change in colorectal. This region also used a mobile mammography van to address screening barriers due to transportation, beginning in 2019. Additionally, Region 3 was the only region to utilize the services of the same practice facilitator from $\mathrm{Y} 1$ to $\mathrm{Y} 7$ of the project, which led to a longstanding relationship between the facilitator and the practices. 
Table 4. Screening Rates for Cancer Types Across 14 Time Points, by Geographic Region

\begin{tabular}{l|ccc|ccc|ccc}
\hline & \multicolumn{3}{|c|}{ Region 1 } & \multicolumn{3}{c|}{ Region 2 } & \multicolumn{3}{c}{ Region 3 } \\
\cline { 2 - 9 } Time point & Colorectal & Breast & Cervical & Colorectal & Breast & Cervical & Colorectal & Breast & Cervical \\
\hline January 2013 & 17.69 & - & - & 36.37 & - & - & 13.41 & - \\
June 2014 & 18.48 & - & - & 39.25 & - & - & 16.27 & - & - \\
August 2014 & 29.55 & 31.34 & 25.91 & 34.37 & 40.89 & 47.41 & 38.30 & 44.49 & 30.96 \\
June 2015 & 32.00 & 47.99 & 25.80 & 41.35 & 49.58 & 49.13 & 49.77 & 55.49 & 44.00 \\
August 2015 & 48.44 & 49.70 & 13.08 & 44.98 & 55.94 & 42.07 & 32.55 & 47.34 & 37.08 \\
June 2016 & 40.77 & 50.74 & 14.61 & 46.28 & 59.45 & 53.25 & 36.36 & 41.99 & 41.48 \\
August 2016 & 42.26 & 61.04 & 17.26 & 47.96 & 53.61 & 47.56 & 33.37 & 40.49 & 41.48 \\
June 2017 & 46.29 & 66.40 & 22.50 & 42.05 & 36.94 & 31.83 & 42.66 & 49.55 & 40.74 \\
August 2017 & 46.29 & 66.40 & 25.90 & 41.54 & 36.94 & 31.80 & 42.46 & 50.28 & 45.46 \\
June 2018 & 58.20 & 49.79 & 31.30 & 34.44 & 29.04 & 27.81 & 48.22 & 53.54 & 48.08 \\
August 2018 & 60.67 & 69.94 & 27.73 & 27.74 & 29.38 & 27.79 & 64.72 & 43.49 & 43.34 \\
June 2019 & 51.46 & 63.32 & 29.97 & 26.50 & 35.90 & 26.00 & 59.08 & 49.17 & 40.97 \\
August 2019 & 59.22 & 63.41 & 27.76 & 36.66 & 34.41 & 26.93 & 58.48 & 49.17 & 44.83 \\
June 2020 & 56.00 & 62.24 & 28.48 & 36.97 & 31.98 & 25.32 & 55.55 & 58.30 & 45.24 \\
Linear trend & & 2.957 & 2.652 & 0.619 & -0.528 & -1.566 & -2.536 & 2.965 & 0.495 \\
& $(<0.001)$ & $(<0.001)$ & $(0.291)$ & $(0.372)$ & $(0.006)$ & $(<0.001)$ & $(<0.001)$ & $(0.543)$ & $(0.273)$ \\
\hline
\end{tabular}

${ }^{a}$ Linear trends summarized by $\beta$ ( $P$-value).

There are potential discrepancies in the way the screening rates were pulled between regions and individual practices. Staff turnover within practices occurred frequently throughout the project, leading to changes in not only who was physically pulling the data but also with the priorities of the practice, the way individuals were trained, and whom they were trained by. Without a way to standardize the queries used to pull screening rates, it is not only feasible but also likely that the pre-PF rates in one year were pulled using a different query than the post-PF rates for that same practice that same year. A complete breakdown of the barriers to and promoters of cancer screening can be found separately. ${ }^{15}$

During Y7, the COVID-19 pandemic began in March 2020 and continued throughout the end of the year. Primary care and other health care services were heavily impacted. Loss of staff, staff reassignment, decrease in office visits, and difficulty in reaching more transient patient populations all negatively impacted screening during this time, which may explain the small decrease seen across all cancer types in Y7. For a deeper look into the impact COVID-19 had on screening, please refer to the article by Schad et al also published in this issue of JPCRR. ${ }^{16}$

\section{Limitations}

To protect the anonymity of the primary care practices that participated in this project, we were limited when exploring facets of organizational linkages or details of regional locations in this manuscript. This QI project was not intended to be conducted as research but rather as a program that was part of a broader cancer prevention strategy rolled out by the New York State Department of Health. The project was an investigator-proposed response to a programmatic call for proposals; as such, we were not able to institute the level of experimental or quasi-experimental control needed to isolate effects. Additionally, our analyses were not powered by large sample sizes because the unit of analysis was each practice. Thus, we were not powered to study the effects of individual practice interventions such as comparing educational media distribution with patient reminder systems. The intervention for the project was considered to be the $\mathrm{PF}$ and $\mathrm{AD}$ provided. Intensive auditing of electronic health records has been observed to be required in order to realize an effect on cancer screening rates. However, we believe our processes were similar and comparable to prior studies. ${ }^{23-25}$ Finally, we believe that one of the cancer types considered by this project fell outside the scope of many of our safety-net practices, with cervical cancer screening not offered at all practices and often managed by local OB/GYN offices instead.

\section{CONCLUSIONS}

Although overall results were mixed, we believe enough improvement was seen to indicate that engagement of safety-net primary care practices by academic centers can have a beneficial impact on promoting screening 
for colorectal and breast cancer. While external funding is often required to activate such projects, the interventions our group conducted are likely achievable by an academic health center or health system that sits at the core of a primary care network. The dedication of external attention, knowledge, and skills brought to safety-net practices by trained facilitators and clinical educators can yield benefits in terms of screening rates. This may be particularly important for safetynet practices exploring how to provide patient-centered screening options to their underserved population of care recipients.

\section{Patient-Friendly Recap}

-As part of a wide-reaching quality improvement project to increase breast, cervical, and colorectal cancer screening, academic instruction and practice facilitation were offered to primary care practices across central and western New York State.

- Average pre- and postintervention screening rates for all participating practices over a 7-year project period were collected annually.

- Colorectal and breast cancer screening at many practices increased over the course of the project. Rates of cervical cancer screening, which in this geographic region is often performed by specialists as opposed to primary care, did not improve.

- Practice-level interventions, when enhanced by facilitation and education, are useful in improving screening rates for some cancer types.

\section{Acknowledgments}

Beyond funding support, this project "took a village" to accomplish. We owe our deepest gratitude to the primary care practices and their teams that participated over the past 7 years and are indebted to the physicians, advanced practice providers, nurses, and practice staff at each site. We also have a large team of past and present project managers, practice facilitators, and community collaborators who contributed to the success of this project. We are extremely grateful to our collaborators at the New York State Department of Health who recognized the value of these efforts and were committed to finding practice-based solutions to increase preventive cancer screening for underserved communities.

\section{Author Contributions}

Study design: Morley, Schad, Tumiel-Berhalter, Brady, Vitale, Norton, Noronha, Swanger. Data acquisition or analysis: Morley, Schad, Tumiel-Berhalter, Brady, Bentham, Vitale, Norton. Manuscript drafting: Morley, Schad. Critical revision: Morley, Schad, Tumiel-Berhalter, Brady, Bentham, Vitale.

\section{Conflicts of Interest}

None.

\section{Funding Sources}

This publication was supported by cooperative agreements NU58DP6102, NU58DP006309, U58DP002029, and U58DP003879, funded by the Centers for Disease Control and Prevention (CDC). Its contents are solely the responsibility of the authors and do not necessarily represent the official views of the CDC or the Department of Health and Human Services, Health Research, Inc., or the New York State Department of Health.

\section{References}

1. Centers for Disease Control and Prevention. Breast cancer: statistics. Last reviewed June 8, 2021; accessed July 22, 2021. https://www.cdc.gov/cancer/breast/statistics/index.htm

2. Hadjipetrou A, Anyfantakis D, Galanakis CG, Kastanakis M, Kastanakis S. Colorectal cancer, screening and primary care: a mini literature review. World J Gastroenterol. 2017;23:6049-58.

\section{$\underline{\text { CrossRef }}$}

3. Institute of Medicine, National Research Council. Potential of screening to reduce the burden of cancer. In: Curry SJ, Byers T, Hewitt M (eds). Fulfilling the Potential of Cancer Prevention and Early Detection. National Academies Press (US); 2003, pp. 156-223.

4. American Cancer Society. Cancer Facts \& Figures 2020. American Cancer Society; 2020.

5. American Cancer Society. Key statistics for cervical cancer. Last revised January 12, 2021; accessed July 22, 2021. https://www. cancer.org/cancer/cervical-cancer/about/key-statistics.html

6. Mader EM, Fox $\mathrm{CH}$, Epling JW, et al. A practice facilitation and academic detailing intervention can improve cancer screening rates in primary care safety net clinics. J Am Board Fam Med. 2016;29:533-42. CrossRef

7. Curry WJ, Lengerich EJ, Kluhsman BC, et al. Academic detailing to increase colorectal cancer screening by primary care practices in Appalachian Pennsylvania. BMC Health Serv Res. 2011;11:112. CrossRef

8. Dignan M, Shelton B, Slone SA, et al. Effectiveness of a primary care practice intervention for increasing colorectal cancer screening in Appalachian Kentucky. Prev Med. 2014;58:70-4. CrossRef

9. Weiner BJ, Rohweder CL, Scott JE, et al. Using practice facilitation to increase rates of colorectal cancer screening in community health centers, North Carolina, 2012-2013: feasibility, facilitators, and barriers. Prev Chronic Dis. 2017;14:E66. CrossRef

10. Cardarelli R, Weatherford S, Schilling J, et al. Improving chronic pain management processes in primary care using practice facilitation and quality improvement: the Central Appalachia Inter-Professional Pain Education Collaborative. J Patient Cent Res Rev. 2017;4:247-55. CrossRef

11. Westfall JM, Roper R, Gaglioti A, Nease DE Jr. Practicebased research networks: strategic opportunities to advance implementation research for health equity. Ethn Dis. 2019;29(Suppl 1):113-8. CrossRef

12. Westfall JM, VanVorst RF, Main DS, Herbert C. Communitybased participatory research in practice-based research networks. Ann Fam Med. 2006;4:8-14. CrossRef

13. Nagykaldi Z, Mold JW, Robinson A, Niebauer L, Ford A. Practice facilitators and practice-based research networks. J Am Board Fam Med. 2006;19:506-10. CrossRef

14. Morley CP. Supporting physicians who work in challenging contexts: a role for the academic health center. $J$ Am Board Fam Med. 2012;25:756-8. CrossRef 
15. Brady L, Tumiel-Berhalter LM, Schad LA, et al. Increasing breast, cervical, and colorectal cancer screenings: a qualitative assessment of barriers and promoters in safety-net practices. J Patient Cent Res Rev. 2021;8:323-30.

16. Schad LA, Brady L, Tumiel-Berhalter LM, et al. Impact of COVID-19 on screening rates for colorectal, breast, and cervical cancer: practice feedback from a quality improvement project. J Patient Cent Res Rev. 2021;8:347-53.

17. Morley CP, Mader EM, Schad L; STFM Resource Library. Increasing colorectal cancer screening through academic detailing and practice facilitation - project summary report August 2014. Posted October 5, 2020; accessed August 17, 2021. https://resourcelibrary.stfm.org/viewdocument/increasingcolorectal-cancer-screen?CommunityKey $=2751 \mathrm{~b} 51 \mathrm{~d}-483 \mathrm{f}-$ 45e2-81de-4faced0a290a\&tab=librarydocuments

18. Mader EM, Bennett BE, Morley CP, Schad L; STFM Resource Library. Increasing breast, cervical and colorectal cancer screening through academic detailing and practice facilitation project summary report July 2015. Posted October 5, 2020; accessed August 17, 2021. https://resourcelibrary. stfm.org/viewdocument/increasing-breast-cervicaland-col? CommunityKey=2751b51d-483f-45e2-81de4 faced0a290a\&tab=librarydocuments

19. Mader EM, Pratte MA, Morley CP, Schad L; STFM Resource Library. Increasing breast, cervical and colorectal cancer screening through academic detailing and practice facilitation - project summary report August 2016. Posted October 5, 2020; accessed August 17, 2021. https://resourcelibrary.stfm.org/viewdocument/ increasing-breast-cervical-and-col-1 CommunityKey $=2751 \mathrm{~b} 51 \mathrm{~d}-$ 483f-45e2-81de-4faced0a290a\&tab=librarydocuments

20. Pratte MA, Morley CP, Schad L; STFM Resource Library. Increasing breast, cervical and colorectal cancer screening through academic detailing and practice facilitation - project summary report August 2017. Posted October 5, 2020; accessed August 17, 2021. https://resourcelibrary.stfm.org/viewdocument/increasingbreast-cervical-and-col-2?CommunityKey $=2751$ b51d-483f45e2-81de-4faced0a290a\&tab=librarydocuments
21. Brady L, Hamouda A, Tumiel-Berhalter L, Schad L, Morley CP; STFM Resource Library. Increasing breast, cervical and colorectal cancer screening through academic detailing and practice facilitation - project summary report August 2018. Posted October 5, 2020; accessed August 17, 2021. https:// resourcelibrary.stfm.org/viewdocument/increasing-breastcervical-and-col-3? CommunityKey $=2751$ b51d-483f-45e281de-4faced0a290a\&tab=librarydocuments

22. Brady L, Bentham A, Tumiel-Berhalter L, Schad L, Morley CP; STFM Resource Library. Increasing breast, cervical and colorectal cancer screening through academic detailing and practice facilitation - project summary report August 2019. Posted October 5, 2020; accessed August 17, 2021. https:// resourcelibrary.stfm.org/viewdocument/increasing-breastcervical-and-col-4

23. Khullar K, Peitzmeier S, Koffman R, Potter J. Impact of electronic documentation on Pap screening rates in an urban health center. J Community Health. 2014;39:416-22. CrossRef

24. Parsons A, McCullough C, Wang J, Shih S. Validity of electronic health record-derived quality measurement for performance monitoring. J Am Med Inform Assoc. 2012;19:604-9. CrossRef

25. Petrik AF, Green BB, Vollmer WM, et al. The validation of electronic health records in accurately identifying patients eligible for colorectal cancer screening in safety net clinics. Fam Pract. 2016;33:639-43. CrossRef

(C) 2021 Advocate Aurora Health, Inc. 